\title{
POLÍTICAS GLOBAIS E LOCAIS: A CAPITALIZAÇÃO DA EDU- CAÇÃO BRASILEIRA E O PAPEL DA SOCIEDADE CIVIL
}

\author{
GLOBAL AND LOCAL POLICIES: the capitalization's brazilian education and civil \\ society role
}

POLITICAS GLOBALES Y LOCALES: la capitalización de la Educação brasileña y el papel de la sociedad civil

\author{
Flávio Caetano da Silva \\ Professor Doutor da Universidade Federal de São Carlos. \\ flaviocaetanoeg@gmail.com \\ José Ricardo Batista \\ Mestrando da Universidade Federal de São Carlos. \\ salgarella@msn.com
}

Raissa Martins Kebbe da Silva Mestranda da Universidade Federal de São Carlos. rkebbe@hotmail.com

\begin{abstract}
RESUMO: Objetivamos, no presente texto, examinar o discurso no qual se enuncia que o Brasil se insere na economia global ao efetivar esforços institucionais que consideram a educação uma alavanca que propulsionará o país para o desenvolvimento semelhante aos dos países centrais do capitalismo, pautado na redução do Estado, emersão do terceiro setor, privatização e parceria público-privado, com vista a uma maior competitividade. Este exame se dará a partir de uma metodologia de cotejamento entre textos de autores clássicos nas teorias de Estado e políticas de amplo escopo (Ball, Sacristán, Teorodo, Pereira) e autores recentes que têm se debruçado sobre as relações entre essas teorias e as realidades locais vivenciadas pelas escolas públicas de educação básica (Andrew e Kouzmin, Fernandes, Brito e Peroni, Libanori, Nogueira, Werle e Barcelos). Segundo esses autores, à educação cabe o papel de formação de consumidores, possuidores de mínimos recursos intelectivos, necessários à inclusão no mercado de trabalho, cumprindo uma agenda de apêndice de medidas gerencialistas. Como resultado desse estudo encontramos uma nova concepção sobre a sociedade civil, sendo aquela que é instada a uma participação ativa desde se mantenha subserviente aos propósitos do Estado sob nova direção. Também podemos indicar como resultado os desdobramentos dessas políticas forjando discursos que enunciam uma educação voltada ao mercado global, marcada pela competição, índices de rendimento, acento em uma concepção de currículo pautado no discurso de inclusão, mas baseado em uma exclusão prática e distanciamento das necessidades de alunos e da melhoria na qualidade de ensino.
\end{abstract}

PALAVRAS-CHAVE: Reforma administrativa. Políticas públicas educacionais globais e locais. Globalização.

ABSTRACT: In this text, we objectify to examine the speech which sets out that Brazil is part of the global economy to effect institutional efforts that consider education a handle to help the country for a similar development like the central capitalist countries, based on the reduction of state, emergence of the third sector, privatization and public-private partnership with a view to greater competitiveness. This examination will take place from a very careful look into the methodology between classical authors texts in the theories of state and broad scope of policies (Ball, Sacristan, Teorodo, Pereira) and also recent authors who have been working on the relationship between these theories and realities local experienced by public schools of basic education (Andrew and Kouzmin, Fernandes, Brito and Peroni, Libanori, Nogueira, Werle and Barcelos). According to these authors, education has the role of consumers formation, holders of minimum intellective resource, needed for inclusion in the labor market, fulfilling an appendix agenda in the management measures. As a result of this study we found a new conception of civil society, and one that is required to actively participate since it remains subservient to state purposes under this new management. We can also indicate as a result the unfolding of these forging political speeches an education to the global market, marked by competition, income indexes, accent on a curriculum design guided the inclusion discourse, but based on a practical exclusion and detachment of students needs and improvement of the quality of education.

KEYWORDS: Administrative reform. Global educational and local policies. Globalization.

$\overline{\text { Artigo recebido em janeiro de } 2016}$

Aprovado em março de 2016 
RESUMEN: Como objetivo, en el presente texto, examinamos el discurso en el cual se enuncia que Brasil se inserta en la economía global al realizar esfuerzos institucionales que consideran a la educación como un impulso para el país que en consecuencia traerá un desarrollo equiparable a los países centrales del capitalismo, pautado en la reducción del Estado, inmersión del tercer sector, privatización y colaboración pública-privada con vista a una mayor competitividad. Este análisis se dará a partir de una metodología de investigación entre textos de autores clásicos en las teorías de Estado y políticas de amplio alcance (Ball, Sacristán, Teorodo, Pereira) y autores recientes que han estado trabajando con relaciones entre teorías y realidades locales vividas por escuelas públicas de educación básica (Andrew y Kouzmin, Fernandes, Brito y Peroni, Libanori, Nogueira, Werle y Barcelos). Según estos autores, en la educación tiene el papel de formación de consumidores y poseedores de mínimos recursos intelectivos necesarios para la inclusión en el mercado de trabajo, cumpliendo una agenda de apéndice de medidas gerencialistas. Como resultado de este estudio encontramos una nueva concepción sobre la sociedad civil, siendo aquella que es solicitada a una participación activa desde que se mantenga subordinada a los propósitos del Estado bajo una nueva dirección. También podemos indicarlo como resultado de los desarrollos de esas políticas forjando discursos que enuncian una educación enfocada al mercado global, marcada por la competición, índices de rendimiento, acento en una concepción de currículum pautado en el discurso de inclusión, pero fundamentado en una exclusión práctica, alejamiento de las necesidades de alumnos y de la mejora en la calidad en la enseñanza.

PALABRAS CLAVE: Reforma administrativa. Políticas públicas educacionales globales y locales. Globalización. 
POLÍTICAS GLOBAIS E LOCAIS | Flávio Caetano da Silva, José Ricardo Batista e Raissa M. K. da Silva

\title{
1| INTRODUÇÃO
}

Organizamos o presente texto em formato de exame teórico em torno de textos acerca de políticas públicas globais e locais, objetivando compreender as relações entre ambas, considerando a análise sobre as percepções de autores sobre o cotidiano das escolas públicas de educação básica. Dividimos o texto em três seções, a saber: Introdução, O global e as Políticas Públicas Educacionais Locais e a Conclusão.

Os estudos realizados no âmbito de disciplinas da pós-graduação em Educação que vimos efetivando nos últimos anos, bem como as ponderações que nos têm sido trazidas por mestrandos e doutorandos, que atuam na educação básica, nos motivou a fazer uma análise da temática que aqui desenvolvemos, em torno das relações entre o global e o local em questões de políticas públicas educacionais. O objetivo do presente artigo é examinar diversas posições teóricas em torno dos discursos que têm se espraiado por diversos setores da sociedade brasileira, sobre temas educacionais, acerca das relações entre políticas de larga escala - aqui denominadas globais - e o local - aqui compreendido como as formas de estabelecer a gestão escolar e os desdobramentos desse embate decorrentes.

Os debates em torno da globalização fizeram surgir necessárias mudanças nas estruturas governamentais e sociais. Em tese, foram subsídios para teorias da nova administração e responsável pela mudança sociocultural sob a égide de discursos perlocucionais, com a finalidade de produzir a impressão de que a administração gerencial é uma proposta progressista de adaptação à globalização avocada pela nova concepção de Estado neoliberal como urgente e eficaz, denominado por Afonso (2007) como a gestão pela qualidade total, cujos efeitos são percebidos no próprio ordenamento jurídico.

Para Ball (2001, p. 101):

\begin{abstract}
A essência da tese da globalização repousa na questão do futuro do Estado Nacional como entidade cultural e política. Essa tese é articulada através dessas perspectivas fortemente inter-relacionadas que têm como referente respectivamente à transformação econômica, política, cultural e social. No caso das duas primeiras, a questão central é se, no contexto da transformação econômica global, os Estados Nação individuais mantém a sua capacidade de conduzir e gerir suas próprias economias face ao poder das corporações multinacionais "descentralizadas", o fluxo e influxo do mercado financeiro global e a expansão da produção industrial moderna. Além disto, perdem também estes Estados Nação individuais a sua autonomia política e econômica perante a crescente amplitude e influência das organizações supranacionais?
\end{abstract}

Afonso (2007) afirma a necessidade de mudança estrutural do Estado brasileiro, pois este transformou-se no principal responsável pela redução das taxas de crescimento econômico. Por isso, o principal argumento do autor assenta-se na ideia de que a crise do Estado é devido ao tamanho do próprio Estado e as propostas de reformas neoconservadoras servem de objetivos não intencionados para seus defensores, indicando, portanto que a reforma do Estado representaria a única saída.

Todavia, a reforma está atrelada à diminuição do Estado e de suas funções. Nessa direção, promoveu-se a expansão do terceiro setor como forma de consolidação de múltiplos "Estados" (NOGUEIRA, 2011). A redução do Estado, a emersão do terceiro setor, os ajustes fiscais, a adaptação às transformações econômicas globais, a ação em ambientes desterritorializados, somados, direcionam para políticas de privatização, terceirização e parcerias público-privado, cujo objetivo é alcançar a ampliação de setores empresariais e sua ascensão sobre a economia nacional, num esforço de se garantir governança e governabilidade. 
Conforme Ball (2001), a principal característica desse ajuste do Estado para seu novo papel configura uma perda da autonomia devido à crescente competição na economia globalizada. Assim, apresentaram-se como principais resultados deste processo a desvalorização dos Estados, assim como, a desorganização de seu aparato técnico e administrativo (NOGUEIRA, 2011), onde o Estado passa a ser visto como um inimigo a ser combatido.

Diante dessa ótica reducionista, a globalização entendida como reorganizadora da produção onde quer que ela esteja ocorrendo, encontrou obstáculos na própria noção de Estado, segundo Nogueira (2011), ao interferir em seu território e sua soberania e como projeto de hegemonia na busca de uma supremacia do mercado e a consolidação de uma cultura mercantil e competitiva. Compreende-se assim que, examinar o fenômeno da globalização supõe um esforço mais profundo. Nesse sentido, vamos nos debruçar sobre ele na próxima seção.

Algumas produções (DALE, 2004; TEODORO, 2003, SANTOS, 2002) indicam que a direção seguida por políticas globais é a da redução do papel do Estado e dos desdobramentos daí decorrentes. Esses estudos, dentre outros, nos remetem ao espaço interno das escolas públicas que, de forma própria e singular, traduzem as demandas políticas que desembarcam no nível local.

\section{2 | O GLOBAL E AS POLÍTICAS PÚBLICAS EDUCACIONAIS LOCAIS}

Aspecto importante da globalização é seu efeito nas políticas públicas educacionais. Apresentadas num conjunto de medidas neoconservadoras, reforçando a fraqueza das instituições democráticas, além das necessárias medidas para preservação do capitalismo, nas quais as estratégias da eficiência e eficácia nas concepções gerencialistas estão intimamente ligadas à ideia de um novo modelo de desenvolvimento e configuram, nesse escopo teórico, única alternativa para melhoria da educação.

Assim, conforme Ball (2001), as políticas nacionais demandam exames mais acurados para que se possa compreendê-las como produto de um nexo de influências e interdependências que resultam numa interconexão, multiplicidade e hibridização dos esforços envidados tanto pelo poder público quanto pela iniciativa privada. É nesse emaranhado de global e local que a estrutura educacional brasileira encontra um dos seus problemas, pois o discurso da eficiência e eficácia está pautado em raízes autoritárias, revestidas de discursos de inovação e participação impondo uma lógica que desembarca no nível local, gerando concepções deterministas, oriundas do nível global.

Ball (2001) sugere podermos identificar que no nível micro, em diferentes Estados, novas tecnologias de políticas têm produzido novas formas de disciplina e que em nível macro, estas disciplinas geram um novo pacto entre Estado e Capital apresentando novos paradigmas da gestão pública focada no racionalismo tecnicista. Para o autor, a responsabilidade local compete ao Estado, como a organização dos recursos, as políticas afirmativas em custos-eficazes e a valorização cultural local que proclamam a escolha gerencial inexoravelmente afirmada em acordos com organismos internacionais (CASTIANO, 2005-2006). Na lógica da divisão da produção científica atual o papel da educação tem sido o de facilitar importação dos saberes e técnicas universais e exportar cérebros locais para os países desenvolvidos.

Portanto, as diversas iniciativas voltadas para adaptação do Estado: leve, ágil, reduzido quase ao mínimo, tomado pela racionalidade técnica, às políticas públicas locais, no dizer de Nogueira (2011) foram igualmente rebaixadas, convertidas a atividades pouco nobres, permeáveis à corrupção, à manipulação, reduzindo-se ao reino da fraude, da força e do desperdício. Diante de tal percepção, as políticas públicas educacionais estariam distanciadas dos cidadãos, servindo a propósitos marcados pelo predomínio de grupos políticos e empresariais elitizados, de cumpri- 
mentos de metas internacionais inserida num contexto econômico sobressalente e potencialmente controlador, como o PISA, como exemplo (LIBANORI, 2015).

Vista como um ramo da economia, a política educacional é reduzida à condição de resultado de uma relação econômica, ou seja, ênfase no mercado, na gestão e no desempenho, tendo como eixo condutor: valores, culturas, subjetividades e formas de disciplinamento. Ball (2001) faz uma crítica a essa tecnologia política, afirmando a necessidade de se rever esse substrato geral (global).

Nogueira (2011) salienta que estamos concentrados no econômico, na estabilidade e no controle do gasto público, quando o papel do Estado deveria ser pensado no sentido de conceber uma nova relação com a sociedade e de se vincular aos destinos da população, à defesa de seus direitos, à promoção de seu bem-estar, cujas metas são de garantir direitos adquiridos e reconhecidos como também, propiciar novas oportunidades de justiça social, de participação política, de representação e de democracia.

Nesse sentido, o processo de tradução de medidas políticas do global para o local, proclamadas como mecanismos que permitem democratizar a gestão educacional exige compreender os discursos políticos, bem como a legislação pertinente ao financiamento e gerência dos recursos destinados à educação, as medidas judiciais e administrativas decorrentes da má aplicação dos mesmos e ainda, expor suas origens e propor o efetivo exercício da participação popular com a finalidade de consolidação de um Estado democrático e socialmente vinculado.

O discurso de políticas brasileiras no campo da educação, desde a década de 1990, assentou-se em quatro pilares ao nosso ver: descentralização, participação, cidadania e sociedade civil, mas que, traduziram-se em práticas de integralização da sociedade civil aos interesses do grande capital. Deixou à livre concorrência a tarefa, do ajuste econômico, à descentralização o papel de democracia, com forte potencial gerencial e envolvimento das esferas de governo locais, atrelada a enunciados de participação, cidadania e sociedade civil.

Nesse sentido, a participação social teria um importante papel nessa política de reorganização do Estado em que os movimentos sociais estavam voltados à gestão política do que para oposição política, valorizando e incentivando um discurso de controle social, mas um controle bem comportado.

Nessa ótica, os interesses gerais das maiorias sociais serviram como um dos fundamentos do Estado democrático, porém, manipulados pelo sistema político com profundas raízes em interesses de corporações de caráter global. Os sujeitos reafirmam o discurso neoliberal, assumem a função estatal de fiscalização e ao mesmo tempo são copartícipes desse mesmo discurso embebido da ideia de formatação da convivência social para soluções dos seus problemas. Tais discursos nos levam a acreditar que basta participação social para a democracia estar presente. Contudo, se em vez disso, desejamos um Estado para dignificar a vida coletiva - um Estado para a sociedade civil, não temos como evitar o anseio por profundas alterações no estado das coisas, rumo a uma configuração democrática de Estado e do social amplas, fortemente concentrada nas finalidades e na dimensão ética do Estado (NOGUEIRA, 2011). É afirmar que existe influência das políticas internacionais e que são revestidas da imagem de progresso, de adesão ao sistema global, o Brasil, neste sentido, está em consonância com os países centrais, e a sociedade civil é uma peça desse quebra-cabeça no qual as medidas políticas buscam controlar os anseios sociais e fortalecer o papel regulador, e a função distributiva da renda, de ampliação de conhecimentos locais em contrapartida à importação de soluções dos problemas econômicos, de cumprimento de metas, unificação de um currículo que valorize a cultura dos países local.

\footnotetext{
${ }_{1}^{1}$ Programme for International Student Assessment (Pisa) - Programa Internacional de Avaliação de Estudantes.
} 
Teodoro (2003) enuncia que a criação de um sistema de organizações internacionais como a ONU, FMI, UNESCO e OCDE deu impulso à internacionalização das problemáticas educacionais, principalmente dos países da periferia que necessitaram cada vez mais da assistência técnica e econômica dessas organizações. Portanto, o recurso estrangeiro funciona como elemento de legitimação das escolhas políticas nacionais.

A interferência dos ditames provenientes das instituições internacionais é visível em questões como indicadores e índices da qualidade de ensino, na estrutura organizacional da educação, nas políticas salariais e na imposição de um currículo comum. Segundo Ball (2001), onde a educação está a cargo do mercado, marcado pela competição, as instituições apelam para economia do valor do/a estudante relacionando diretamente ao financiamento e indicadores de desempenho como informações de mercado, os custos educacionais e da reputação do/a estudante e não a seus interesses e necessidades que passam a ser centrais na resposta dos produtores, desdobrando-se em um currículo oculto, ou seja, o aluno aprenderá aquilo que se apresenta como mercadoria, cabendo ao Estado a função de regulação, auditoria, prescrição das políticas educacionais e unidade de prestação de serviço, ou seja, em conformidade com aquilo definido pela OCDE, Estado mínimo que controla à distância.

Fernandes, Brito e Peroni (2012) nos fornecem valiosas contribuições a respeito das relações público-privado, afirmando que nos últimos anos, cada vez mais, o setor privado interfere no setor público como parte de um diagnóstico de que o Estado é ineficiente e o setor privado mercantil deve ser coordenador da vida em sociedade. As autoras analisam a política educacional atual focando a posição do Estado, que por sua vez, está inserido em um movimento maior do capitalismo, estabelecendo um cenário no qual, a tentativa de superar sua crise indica como significativas estratégias: o neoliberalismo, a globalização, a reestruturação produtiva e a terceira via. Ball (2001, p. 112), nos adverte que o papel do Estado se apresenta sob nova configuração, mas não extinto, ao ponderar sobre o tema em tela:

Não estou afirmando que, apesar dos esforços de agências como a OCDE, as políticas de educação nacional são, em sua totalidade, uma transposição da agenda educacional global ou que os Estados Nação perderam o controle total sobre as suas decisões políticas, decisões, estas tomadas dentro da lógica do mercado global. A educação tem um conjunto complexo de relações com e no seio dos processos de globalização.

A educação está marcada pelas imposições do mercado e ascensões do capitalismo estreitamente global, de tal forma, que novos enunciados vão emergindo no cenário das políticas públicas, destacando-se, dentre eles a sociedade de aprendizagem, economia baseada no conhecimento, impregnado nas políticas educativas sob o império das políticas econômicas. Nesse sentido, há de se pensar se as políticas locais convergem para uma política de consenso ou as políticas difundidas e impostas como "epidemias políticas" mascaram a falta de debates sobre os princípios educativos (BALL, 2001).

Várias questões surgem dessa análise como, por exemplo, como o sistema educacional é afetado por processos de globalização que ameaçam a autonomia de sistemas educacionais nacionais e a soberania do Estado em sociedades democráticas? Ou, de que forma a globalização está alterando sistemas educacionais que têm por princípio integrarem-se em uma comunidade? São questões de elevado potencial para que se produzam novas pesquisas e se examine mais detidamente as relações entre os movimentos sociais democratizantes e a cooptação pelas elites governantes e empresariais das bandeiras sociais que emergiram em passado recente, como a década de 1980.

Burbules e Torres (2004) afirmam que apesar das mudanças inegáveis, os efeitos da globalização, às vezes, são exagerados. O que se vê é uma segmentação (mundial) entre a cultura glo- 
balizada - por exemplo, a prevalência de um habitus urbano e cosmopolita - e o resto do mundo, que enxerga poucos dos benefícios - até onde eles existem - do acesso ao mercado global ou a culturas cosmopolitas. A palavra "globalização" frequentemente é usada para reforçar a sua inevitabilidade e, dessa forma, para suprimir tentativas de resistir às injunções de nível global.

O que os autores nos propõem auxilia-nos a esclarecer a dicotomia do local-global, uma vez que o currículo pode ser uma fonte imensurável de disseminação dos discursos dos países centrais ou eixo articulador dos conhecimentos locais com os universais, como significativo exemplo.

Fernandes, Brito e Peroni (2012) afirmam que a iniciativa público-privada acaba por redefinir o conteúdo das políticas públicas de educação. É a lógica privada mercantil no sistema público, influenciando tanto a gestão quanto o currículo das escolas.

Certamente a orientação de políticas de amplo espectro como o PISA, contribuem para o estabelecimento de algo próximo a um currículo global e está coerente com os princípios educativos, sociais de aprendizagem e economia do conhecimento, ou seja, tomada de forma pragmática, servindo aos interesses do conservadorismo, mas quem se beneficiaria com o currículo nacional é sem dúvida o Estado Regulador, conforme podemos apurar dos escritos de Libanori (2015). Com o apoio nos textos de Sacristán (2013, p. 42), no tocante às discussões acerca do currículo identificamos que um notável processo de ressignificação está em curso:

O currículo passa, de tal modo, por um processo de produção de efeitos de verdade como Foucault (1999) os chamaria, retomando a herança nietzschiana - até ser considerado um campo ou uma arena de conflitos, um espaço no qual entram em jogo político as ações de poder sob regras - questionadas - que ditam o controle - não aceito - sobre curso do desenvolvimento e velam pela - discutível - licitude dos procedimentos [...].

Enfim, os questionamentos giram em torno do que é conhecimento local e o que é conhecimento universal. Se esse local for visto de forma homogênea acabamos universalizando-o. Castiano (2005-2006) argumenta que o currículo local não é só um espaço de integração de saberes, valores e práticas locais no currículo nacional, mas, sobretudo e potencialmente, um espaço de negociação, avaliação e validação dos saberes de ambas as naturezas. Dessa forma, é importante o reconhecimento acerca da validade dos dois conhecimentos, mas não a partir de uma dualidade social (tradicional versus local) na qual esses saberes se mostram em conflitos entre si, mas sim a partir de uma coexistência entre ambos. Com o autor afirmamos que o currículo local, com possibilidade de aprender os saberes locais em idiomas locais, é um importante passo dado na direção de uma educação que permita subverter a extroversão, desmarginalizar e desmistificar os saberes locais.

Nessa perspectiva, a ênfase das discussões sobre o currículo local assenta-se sobre a possibilidade de abrir mais espaço para que os saberes locais sejam acolhidos na escola básica, sendo que não deve figurar, apenas, como uma disciplina à parte, senão um conjunto de conteúdos determinados como sendo relevantes para a aprendizagem aplicável nas diferentes disciplinas do Currículo Nacional, mas aspirações que a comunidade entende serem relevantes para os estudantes aprendam na escola.

A maior dificuldade encontrada para a implantação do currículo local é que ele tende a exigir muito tempo de pesquisa e sistematização e alguns deles quebram normas e tradições existentes. O professor deixa de ser apenas um reprodutor do conhecimento e passa a ser um investigador de novos saberes, oriundos do local em que se insere a escola. Essa questão demanda formação para tal postura e ao mesmo tempo vontade política para a efetivação dessa demanda.

O argumento para a implantação do currículo local se deposita na possibilidade da escola se apropriar dos saberes depositados nas comunidades sendo que os estudantes poderão ter, ao mesmo tempo, oportunidade e o direito de confrontarem sua cultura com aspectos culturais que 
Ihe são exteriores, de modo a estabelecer novos diálogos com o conhecimento amplo que chega a eles, podendo configurar profícuas analogias e realizar escolhas que se lhes tornarem exequíveis.

A escola tornar-se-ia assim, espaço da existência seletiva, transformando-se e articulando estratégias para que o currículo local se torne um espaço integrador crítico e criativo e não um espaço de assimilação cultural com novas roupagens. A coexistência já não será silenciosa, mas com ambos conhecimentos - local e global - em confronto, pode-se vislumbrar a possibilidade de transcendência para uma coexistência ativa, pois o que se pretende alcançar é o fortalecimento do local frente ao global, bem como de alunos e das comunidades em que vivem frente às instituições que ali estão presentes, de modo que eles possam avaliar saberes diante das práticas e valores que trazem consigo.

Na esfera educacional, os movimentos de pressão de entidades, cuja atuação tem alcance mundial, exercem potentes determinantes nas políticas locais. O processo de mundialização da economia e dos saberes é sentido em todos os aspectos educacionais, desde o financiamento até o currículo. É difundida a perspectiva de que os países periféricos seguirão o mesmo desenvolvimento dos países centrais, quando na verdade, há uma relação de preponderância na manutenção do status quo e uma configuração da estratigrafia social que gera divisores internos no local e que emergem na relação entre a periferia e semiperiferia e outros setores da sociedade. Isso também pode ser afirmado entre diferentes extratos de nações, dividindo-as em espaços privilegiados e plenos em atendimento aos direitos civis, por um lado e bolsões de pobreza e um significativo contingente de marginalizados, por outro. Assim, a educação passa por transformações impostas pela economia e é fortemente difundida a proposta teórica da necessidade de adequação à globalização, o trecho abaixo, retirado do site do MEC reafirma a posição do Brasil,

Os desafios que o Brasil deve enfrentar para aumentar sua participação na economia
global foram tema de debate no $8^{\circ}$ Encontro Nacional da Indústria (Enai), realizado em
Brasília. "Sabemos que para superar os desafios que temos pela frente a questão educa-
cional é essencial", afirmou o secretário-executivo do Ministério da Educação, Henrique
Paim. Ele lembrou que o despertar para a educação surgiu recentemente no Brasil. Paim
destacou o crescimento da educação profissional, a ampliação das instituições e a ex-
ecução do Programa Nacional de Acesso ao Ensino Técnico e Emprego (Pronatec), além
da importância do ensino técnico, que prepara adequadamente as pessoas para o mundo
do trabalho. Pronatec - Entre as parcerias bem sucedidas com o setor privado está o Pro-
natec, cujo principal parceiro do governo é o Serviço Nacional de Aprendizagem Industrial
(SENAI). Neste ano, o programa alcançou mais de 5,4 milhões de matrículas. O dobro do
ano passado. (BRASIL, 2013).

Portanto, os processos de globalização, que comportam diversas atividades econômicas e as decisões tomadas em seu interior, impôs uma nova agenda ao mercado e a consolidação de uma cultura mercantil ainda mais competitiva. A burocracia estatal de vilã passou a perpetuar o discurso neoconservador e a sociedade civil passou a desempenhar funções estatais e de afirmação da nova política global que impõe descentralização, redução dos custos operacionais, sustentabilidade e controle social. Diante de tais mudanças, a própria compreensão do que vem a ser descentralização está fortemente ligada a outras ideias como participação, cidadania e democracia. Todas juntas compõem, atualmente o novo arcabouço teórico-enunciativo do capital.

As políticas públicas educacionais locais tendem a moldar-se frente aos ditames dos países centrais, revelando a participação popular mais como fortalecimento de discursos democráticos do que propriamente garantias de atendimento de amplos anseios sociais. Neste caso, as diferentes formas de participação e controle social, notadamente, os conselhos educacionais, situados no âmbito de escolas públicas ou no âmbito municipal - Conselhos Escolares e Conselhos 
Municipais de Educação, respectivamente - são convertidas em movimento de maximização de interesses que, tanto podem ser legítimos daqueles que demandam por uma educação de qualidade, ampla e democrática, quanto daqueles que intencionam aparelhar as formas de intervenção social nas decisões do poder público, desviando-os do exercício de um papel mais efetivamente crítico e transformando-os em apêndice dos núcleos de decisão educacionais.

\section{3 | CONSIDERAÇÕES FINAIS}

Os desdobramentos no campo educacional, em torno das políticas globais e locais em termos de educação básica, nos instigaram a examinar o discurso de que o Brasil necessita participar da economia global, superar desafios econômicos e transformar a educação numa alavanca que propulsionará para um desenvolvimento semelhante aos dos países centrais. Todavia, essas mudanças tendem a fazer com que os Estados Nação percam autonomia política e econômica perante tamanha força da qual o mercado é o principal detentor.

Os principais fundamentos para que o país saia da crise e entre no novo mercado são a diminuição do Estado e de suas funções, emersão do terceiro setor, privatização e parceria público-privado, com a finalidade de alcançar um Estado mais competitivo que garanta a governança e a governabilidade.

A educação assume o papel de reforçar tais medidas gerencialistas, exaltando a eficiência e eficácia como parâmetros centrais. Outro aspecto importante, é que a globalização expõe uma cultura à outras num movimento centro-periferia, facilitando a exportação de saberes e ao mesmo tempo importando soluções e tecnologia política.

Outro aspecto digno de nota, que a reforma administrativa ocasionou, refere-se à emersão de um Estado democrático de direito com participação efetiva da sociedade civil. No entanto, o que se verificou nesses anos foi uma sociedade civil servindo aos propósitos do capital, desqualificada e despreparada para assumir o papel de efetivo controle social sobre decisões políticas que afetam as mais amplas demandas da sociedade. Diante disso, as políticas educacionais são entendidas como ajustamento e adequação das estruturas econômicas, transferindo à iniciativa privada muitas de suas tarefas essenciais, pautadas na competição, índices de rendimento e distanciamento das reais necessidades da comunidade escolar, o que faz emergir um novo currículo criado para atender a esse mercado global.

A relação público-privado acaba por redefinir o conteúdo das políticas públicas de educação tendo como reflexo a imposição de uma base curricular comum, o que faz ressurgir a importância da discussão sobre o currículo local, uma vez que ao estabelecer uma base curricular comum, conhecimentos acerca da própria cultura acabam à margem das políticas curriculares e de amplos interesses societários. Portanto, entendemos a necessidade da escola, considerada como espaço da coexistência dos currículos global e local, de afirmar suas concepções e suas configurações culturais, para que se consolide como um local integrador e crítico, e não apenas de assimilação cultural.

O Estado mínimo obriga outros entes da federação a participar de forma mais ativa nas políticas educacionais, mas como meros reprodutores de estratégias globalizadas, marcada por acordos com organismos internacionais, desvinculadas da realidade e necessidade locais, impondo metas, ajustes fiscais e econômicos, potencializando a cultura dos países centrais. Pelas razões aqui expostas, formou-se uma nova sociedade civil para apoiar a imposição das novas injunções do capital e a ideia-força de que os países periféricos chegarão ao centro, quando na verdade, há uma relação de dominação e o fortalecimento de forças centrífugas, que tendem a garantir o afastamento do local e suas demandas em função das pressões globais. 
POLÍTICAS GLOBAIS E LOCAIS | Flávio Caetano da Silva, José Ricardo Batista e Raissa M. K. da Silva

\section{Referências}

AFONSO, A. J. Estado políticas educacionais e obsessão avaliativa. Contrapontos, Itajaí, v. 7, n. 1, p. 1122, jan./abr. 2007.

ANDREWS, C. W.; KOUZMIN, A. O discurso da nova administração pública. Lua Nova, n. 45, p. 97-129, 1998. Disponível em: <http://www.scielo.br/pdf/In/n45/a05n45. pdf>. Acesso em: 02 set. 2014.

BALL, S. J. Diretrizes políticas globais e relações políticas locais em educação. Currículo sem Fronteiras, v. 1, n. 2, p. 99-116, jul./dez. 2001. Disponível em: <http:/l www.curriculosemfronteiras.org/vol1iss2articles/ball. pdf>. Acesso em: 16 dez. 2014.

BRASIL. Ministério da Educação. Participação na economia global exige investimento em educação. Brasília, DF: MEC, 2013. Disponível em: <http:// portal.mec.gov.br/index.php?option=com_content\&view=article\&id=20030:participacao-na-economia-global-exige-investimento-em-educacao\&catid=209\&ltemid=86>. Acesso em: 07 jan. 2015.

BURBULES, N.C. e TORRES, C.A. Globalização e Educação: Uma Introdução. In: Globalização e Educação Perspectivas críticas. BURBULES, N. C. e TORRES, C. A. (orgs.) Porto Alegre: 2004, Artmed Editora. p. 11-25.

CASTIANO, J. P. O currículo local como espaço social de coexistência de discursos: estudo de caso nos distritos de Báruè, de Sussundenga e da cidade de Chimoio - Moçambique. Revista E-Curriculum, São Paulo, v. 1, n. 1, dez./jul. 2005-2006. Disponível em: <http://www. redalyc.org/html/766/76610103/>. Acesso em: 07 out. 2014.

DALE, R. Globalização e educação: demonstrando a existência de uma "Cultura Educacional Mundial Comum" ou localizando uma "Agenda Globalmente Estruturada para a Educação"? Revista Educação \& Sociedade, Campinas, v. 25, n. 87, p. 423-460, maio/ago. 2004. Disponível em: <http://www.scielo.br/pdf/es/v25n87/21464. pdf>. Acesso em: 05 mar. 2016.
FERNANDES, M. D. E; BRITO, S. H. A.; PERONI, V. M. V. Sistema e plano nacional de educação: notas sobre conceituação, relação público-privado e financiamento. Revista Brasileira de Estudos Pedagógicos, Brasília, v. 93, n. 235, set./dez. 2012. Disponível em: $<$ http://www.scielo.br/scielo.php?script=sci_arttext\&pid=S2176-66812012000400002\&lng=en\&nrm=iso $>$. Acesso em: 11 maio 2015.

LIBANORI, G. A. Melhores politicas para melhores vidas: um estudo crítico das concepções que embasam o Programme For International Student Assessment (PISA) no período 1997-2012. 2015. 159 f. Tese (Doutorado em Educação) - Universidade Federal de São Carlos, São Carlos, 2015.

NOGUEIRA, M. A. Um estado para a sociedade civil: temas éticos e políticos da gestão democrática. 3. ed. São Paulo: Cortez, 2011.

SACRISTÁN, J. G. Saberes e incertezas sobre o currículo. Porto Alegre: Penso, 2013.

SANTOS, B. S. Reinventar a democracia. Lisboa: Gradiva, 2002. Disponível em: <http://www.boaventuradesousasantos.pt/media/Reinventar\%20a\%20Democracia Gradiva_1998.pdf>. Acesso em: 05 mar. 2016.

TEODORO, A. Globalização e educação. São Paulo: Cortez, 2003.

WERLE, F. O. C.; BARCELLOS, J. A. S. Plano municipal de educação e a afirmação de princípios para a educação local. Ensaio: Avaliação e Políticas Públicas em educação, Rio de Janeiro, v. 16, n. 61, out./dez. 2008. Disponível em: <http://www.scielo.br/scielo.php?script=sci arttext\&pid=S0104-40362008000400003\&Ing=pt\&nrm=iso>. Acesso em: 16 dez. 2014. 